\title{
Improvement of Xylose Utilization and L-ornithine Production by Metabolic Engineering of Corynebacterium glutamicum
}

\author{
Ge Gao ${ }^{1}$, Yan Zhang ${ }^{2}$, Ying Zhou ${ }^{1}$, and Bang-Ce $\mathrm{Ye}^{3}$ \\ ${ }^{1}$ East China University of Science and Technology \\ ${ }^{2}$ Shihezi University \\ ${ }^{3}$ State Key Laboratory of Bioreactor Engineering
}

September 11, 2020

\begin{abstract}
L-ornithine is a basic amino acid, which shows significant value in food and medicine industries. There is a huge space for L-ornithine production with strains available for metabolic engineering, and it is urgent to develop a high-efficiency engineering strain for industrialization. Here, xylose isomerase and xylulose kinase were introduced into Corynebacterium glutamicum S9114 to establish xylose metabolism pathway, and then xylose became a substitute carbon source of glucose. In addition, the optimization and overexpression of phosphoenolpyruvate carboxylase and pentose transporter have been conducted to promote the synthesis of L-ornithine for the first time. Furthermore, though optimizing the concentration ratio of glucose and xylose (7:3), adding biotin and thiamine hydrochloride, we arrived at the highest L-ornithine yield $41.5 \mathrm{~g} / \mathrm{L}$ in shaking flask fermentation so far. Our results demonstrate that the combination of metabolic engineering and the optimization of fermentation process can make great potential for L-ornithine production by lignocellulose hydrolysate.
\end{abstract}

Improvement of Xylose Utilization and L-ornithine Production by Metabolic Engineering of Corynebacterium glutamicum

Ge Gao ${ }^{1 \#}$, Yan Zhang ${ }^{2 \#}$, Ying Zhou ${ }^{1 *}$, Bang-ce Ye ${ }^{1,2 *}$

1: Laboratory of Biosystems and Microanalysis, State Key Laboratory of Bioreactor Engineering, East China University of Science and Technology, Shanghai 200237, China; 2: School of Chemistry and Chemical Engineering, Key Laboratory for Green Processing of Chemical Engineering of Xinjiang Bingtuan, Shihezi University, Shihezi, 832003, China.

*Corresponding author:zhouying@ecust.edu.cn; bcye@ecust.edu.cn;

\section{ABSTRACT}

L-ornithine is a basic amino acid, which shows significant value in food and medicine industries. There is a huge space for L-ornithine production with strains available for metabolic engineering, and it is urgent to develop a high-efficiency engineering strain for industrialization. Here, xylose isomerase and xylulose kinase were introduced into Corynebacterium glutamicum S9114 to establish xylose metabolism pathway, and then xylose became a substitute carbon source of glucose. In addition, the optimization and overexpression of phosphoenolpyruvate carboxylase and pentose transporter have been conducted to promote the synthesis of L-ornithine for the first time. Furthermore, though optimizing the concentration ratio of glucose and xylose (7:3), adding biotin and thiamine hydrochloride, we arrived at the highest L-ornithine yield $41.5 \mathrm{~g} / \mathrm{L}$ in shaking flask fermentation so far. Our results demonstrate that the combination of metabolic engineering and 
the optimization of fermentation process can make great potential for L-ornithine production by lignocellulose hydrolysate.

Keywords: L-ornithine; Corynebacterium glutamicum ; Xylose; Metabolic engineering

\section{INTRODUCTION}

L-ornithine is non-proteinogenic amino acid, which is an important intermediate product of the urea cycle pathway. It is a downstream product of glutamate and a key precursor for the production of L-citrulline, L-proline and L-arginine. L-ornithine has attracted special attention for its biological functions (Sivashanmugam, J, V, \& K, 2017), and is widely used in daily health care and disease treatment such as the positive effect on the protection and vitality recovery of human liver and the heart (Butterworth, 2020; Das et al., 2020; Davies et al., 2009), improving visual function (Sakamoto, Mori, Nakahara, Morita, \& Ishii, 2015), regulating the secretion of hormones (Matsuo et al., 2015). Moreover, a recent report demonstrates that Lornithine as raw material has a great prospect for the development of new anticancer drugs (Vargas-Ramírez et al., 2016).

Corynebacterium glutamicum is the most important amino acids producing strain in the past 40 years, such as glutamate, L-alanine, L-serine, L-arginine, and L-proline (Gutmann, Hoischen, \& Krämer, 1992; Jensen, Eberhardt, \& Wendisch, 2015; Jojima, Fujii, Mori, Inui, \& Yukawa, 2010; Park et al., 2014; X. Zhang et al., 2018). AlthoughE. coli and Saccharomyces cerevisiae have ever been engineered to be the producer of L-ornithine (Becker \& Wittmann, 2015; Lee \& Cho, 2006; Qin et al., 2015), C. glutamicum, which produces large amounts of glutamate, the precursor of L-ornithine, still to be the preferred dominant strain (Zhang, Yu, Zhou, \& Ye, 2018). The concentration of intracellular glutamate is an important driving force for L-ornithine production.

Random mutation together with genetic and metabolic engineering are two key methods in the breeding process for L-ornithine production by C. glutamicum. However, the random mutation breeding has many disadvantages, including the complex screening process, low success rate, high probability of reverse-mutation. Those made directed genetic metabolic engineering to be the priority option. A series of measures were taken to increase the L-ornithine production by genetic engineering modification (Wu, Guo, Zhang, Jiang, \& Ye, 2019). First, focused primarily on the main L-ornithine synthesis pathway (Hao et al., 2016; Jensen et al., 2015; Jiang, Zhang, Li, \& Liu, 2013; D. J. Kim, Hwang, Um, \& Cho, 2015; Q. Shu et al., 2018; Zhang, Ren, Yu, Zhou, \& Ye, 2018; Zhang, Yu, Zhou, Li, \& Ye, 2017); second, the transportation of L-ornithine amino acids (B. Zhang, L. Q. Ren, et al., 2018); last, based on glycolysis, acetic acid metabolism, pentose phosphate pathway (S. Y. Kim, Lee, \& Lee, 2015; Zhang, Yu, Wei, \& Ye, 2018), the tricarboxylic acid cycle and glucose utilization pathway (Ikeda et al., 2011; Lindner et al., 2013; Lindner, Seibold, Henrich, Kramer, \& Wendisch, 2011; Xu, Zhang, Liu, \& Zhang, 2016; Zhang, Gao, Chu, \& Ye, 2019; Zhou, Wang, Xu, Chen, \& Cai, 2015). In addition to rational modification, adaptive evolution strategies combined with transcriptional levels analysis provides another strategy to develop a strain with high performance (Jiang, Chen, Zhang, \& Liu, 2013). Jensen et al. constructed $C$. glutamicum ORN6 by knocking out $\arg F$, $\arg R$ and $\arg G$, attenuating the expression of $p g i$ and increasing the copy number of the arginine operon $\operatorname{argCJB}{ }^{\mathrm{A} 49 \mathrm{~V}, \mathrm{M}_{4} \mathrm{~V}} \mathrm{D}$ on the chromosome, the L-ornithine yield was $0.52 \mathrm{~g} / \mathrm{g}$ (Jensen et al., 2015). Hwang et al. knocked out ncgl2053 , ncgl0281 andncgl2582 that encoding $\mathrm{NADP}^{+}$-dependent oxidoreductase, which resulted in the loss of glucose dehydrogenase activity and the increasing of 6-phosphate gluconate dehydrogenase activity. The production of L-ornithine is $66.3 \%$ higher than that of the starting strain (Hwang \& Cho, 2014). Shu et al. deleted proBand $\arg F$ to block the branch of the L- ornithine synthesis pathway, mutated $\operatorname{Arg} B$ and expressed heterologous $\arg A$ and $\arg E$ to introduce an artificial linear transacetylation pathway. The production of L-ornithine was 40.4g/L in 5-L bioreactor (Qunfeng Shu et al., 2018). Zhang et al adopted a series of genetic engineering modifications to achieved the maximum L- ornithine yield of $43.6 \mathrm{~g} / \mathrm{L}$ in fed batch fermentation by far (Zhang et al., 2019). Although many strategies have been adapted to increase the production of L-ornithine, how to build a more efficient industrial strain with practical applications is still a long way off. 
In order to make good use of the most abundant renewable resources and do not compete with people for food, a large amount of studies have focused on how to construct an efficient microbial cell factory utilizing xylose and glucose as mixed carbon sources in the past fifteen years (Becker, Rohles, \& Wittmann, 2018). Thanks to the weak carbon catabolite repression, C. glutamicum is regarded as a major industrial force with great potential in recent years (Buschke, Schafer, Becker, \& Wittmann, 2013; Wendisch et al., 2016). However, due to C. glutamicum lacks of xylose isomerase (XylA), it could not grow on medium containing xylose as the sole carbon source. Buschke et al. and Gopinath et al. used the exogenous xylose isomerase (XylA) and xylulose kinase (XylB) to establish the isomerase pathway in C. glutamicum to realize the utilization of xylose (Buschke, Becker, et al., 2013; Gopinath, Meiswinkel, Wendisch, \& Nampoothiri, 2011). Five copies of xylAB operon from $E$. coli were integrated to $C$. glutamicum $\mathrm{R}$ chromosome to generate the strain $\mathrm{X} 5 \mathrm{C} 1$, which could consume $40 \mathrm{~g} / \mathrm{L}$ glucose and $20 \mathrm{~g} / \mathrm{L}$ xylose in 12h (Sasaki, Jojima, Inui, \& Yukawa, 2008). In addition, several other strategies were adopted to improve the xylose utilization, including the introduction of arabinose transporter (Brusseler et al., 2018; H. Kim et al., 2017), overexpressing of TAL/TKT in the pentose phosphate pathway (Jo et al., 2017). Meiswinkel et al. constructed an engineered strain C. glutamicum PUT21 by introducing $x y l A$ from $X$. campestris, $x y l B$ from $C$. glutamicum and $\arg B A D$ operon from $E$. coli to produce $2.59 \mathrm{~g} / \mathrm{L}$ of L-ornithine, and the volumetric ornithine productivity is $43.2 \mathrm{mg} /(\mathrm{L}[?] \mathrm{h}$ ) (Meiswinkel, Gopinath, Lindner, Nampoothiri, \& Wendisch, 2013). In addition to xylose isomerase metabolic pathway, Christian

et al. introduced the $x y l X A B C D$ operon from Caulobacter crescentus into C. glutamicumATCC13032 to establish the Weinberg pathway (Brusseler et al., 2018). Although the utilization of xylose by C. glutamicum has already been realized, the utilization rate of xylose is still unsatisfied. More modified strategies are needed to improve the utilization rate of xylose and the production of L-ornithine., which opened the door to the efficient utilization of lignocellulose.

In our previous studies, we have successfully constructed the C. glutamicum SO26 with high L-ornithine yield (Zhang et al., 2019; B. Zhang, L. Q. Ren, et al., 2018). In this study, we attempted to utilize the most abundant carbon source in lignocellulose hydrolysate - glucose and xylose. We adopted the approaches of metabolic engineering and fermentation process control to accelerate the xylose consumption rate and the yield of L-ornithine. First, a more efficient $x y l A B$ operon was screened out from different strains, and the arabinose transporter araE from Bacillus subtilis was knocked into theiolR locus under the promoter $\mathrm{P}_{\text {eftu }}$. Second, the acetylation of phosphoenolpyruvate carboxylase (PEPC) was reduced to release the feedback inhibition of aspartic acid, and a strong constitutive promoter $\mathrm{P}_{\mathrm{H} 36}$ was introduced in the upstream of pepc . The strain after a series of modulations is named C. glutamicum XAB03. Finally, though the optimization of fermentation process, we found the concentration ratio of glucose and xylose (7:3) and the coenzyme addition (biotin $0.9 \mu \mathrm{M}$ and thiamine-HCl $15 \mu \mathrm{M}$ respectively) can realize the highest L-ornithine yield $41.5 \mathrm{~g} / \mathrm{L}$ in shaking flask fermentation up to date. All the metabolic engineering process are shown in Fig.1. Schematic diagram.

\section{MATERIALS AND METHODS}

\section{Bacterial strains, plasmids and primers}

The strain SO26 originated from C. glutamicum S9114 underwent a series of modifications (deletion of $\operatorname{argF}$ , ncgl1221 , argR , putP , iolR, and mscCG2 ; attenuation ofodhA, proB , pta, cat, and ncgl2228 ; and overexpression of lysE, gdh, gdh2, cg3035, pfkA, pyk, glt, tkt ,argCJBD, and iolT1) was used as a starting strain for further metabolic engineering in this study. E. coli DH5 $\alpha$ was used as host for rapid replication of recombinant plasmids. Xylose isomerase $(x y l A)$ and xylulose kinase $(x y l B)$ were amplified from E. coli K-12 MG1655 and X. campestris. The arabinose transporter (araE) were derived from Bacillus subtilis . All the strains and plasmids used in this study are presented in Table 1. 


\section{Construction of plasmids and strains}

The basic DNA manipulation and strain construction was operated according to the standard molecular cloning manual.E. coli DH5 $\alpha$ was used as the host of gene cloning. All the primers used in this study are presented in Table S1 (Supplementary Information). The suicide vector pK18mobsacB containing the sucrose lethal gene $s a c B$ was used to delete or integrate gene on chromosome.

The xylAB gene clusters from E. coli and $X$. campestris were amplified by primers EAB-F/EAB$\mathrm{R}$ and XAB-F/XAB-R respectively, the inserted restriction sites areHind III/EcoR I and Hind III/Sac I of pXMJ19. The plasmids pXMJ19, p19P $\mathrm{P}_{\text {lac }}-\mathrm{EcoAB}$, and $\mathrm{p} 19 \mathrm{P}_{\text {lac }}-\mathrm{XcaAB}$ were transformed into $C$. glutamicumSO26 to produce strains $C$. glutamicum $\mathrm{pX} 、 \mathrm{EAB} 、 \mathrm{XAB}$. AraEfrom B. subtilis with a constitutive $\mathrm{P}_{\text {eftu }}$ promoter were amplified by araE-F/araE- $\mathrm{R}$ and up-eftu$\mathrm{F} /$ araE-eftu-R respectively. The product of fusion PCR was inserted into the EcoR V site of plasmid pk18-iolR byGibsonassembly,andthengeneratedtherecombinantplasmidpk18 $-P_{\mathrm{eftu}}-^{i}$ olR $::$ araEandcorrespondingstrain $X A B 01$.

To increase PEPC expression by lowing the acylation of PEPC, a synthesized strong promoter H36 was inserted in the upstream of pepc gene (Yim, An, Kang, Lee, \& Jeong, 2013), and then the AAG bases from 1957 bp to 1959 bp were mutated to CGC by overlap PCR, the primer up-HA-F1 / up-HA-H36-R2 amplified pepc upstream homology arm sequence, primer up-HA-H36-F3 / pepc-H36-R4 amplified H36 promoter, primer mutant-(KR)-F/down-HA-pepc-R8 realizes the base mutation of K653R, pepc-H36-F5/mutant-(KR)$\mathrm{R}$ amplifies the pepc upstream homology arm sequence, primer down-HA-pepc-F9/down-HA-R10 amplified the homology arm sequence downstream of pepc. Finally, the entire fragment was combined by Gibson assembly under the primer up-HA-F1/down-HA-R10, resulted the recombinant plasmid pk18- $\mathrm{P}_{\mathrm{H} 36}-$ pepc T1. Furthermore, to reduce the feedback inhibition of aspartic acid on PEPC, the same operation has been done at 895-897 bp AAC to replace GAT, amplification using pepc-H36-F5/D299N-R6 and D299N-F7/down-HApepc-R8 with pk18- $\mathrm{P}_{\mathrm{H} 36}$-pepc $\mathrm{T} 1$ as a template can realize base mutation of $\mathrm{D} 299 \mathrm{~N}$, forming the pk18- $\mathrm{P}_{H 36}$ - рерс T2, resulted in the strain C. glutamicum XAB03. Primers pXMJ19-F/pXMJ19-R and M13 fwd/M13 rev are verification primers for pXMJ19 and pK18mobsacB, respectively.

All the recombinant plasmids were constructed in E. coli $\mathrm{DH} 5 \alpha$ and transformed into C. glutamicum by electroporation. The mutant strains were screened through two rounds of homologous recombination, and further confirmed by colony PCR and sequencing.

\section{Cultivation medium and conditions}

Luria-Bertani (LB) medium containing $\mathrm{NaCl} 10 \mathrm{~g} / \mathrm{L}$, tryptone $10 \mathrm{~g} / \mathrm{L}$ and yeast extract $5 \mathrm{~g} / \mathrm{L}$ were used for cultivation of $C$. glutamicumand $E$. coli . Antibiotic was added to the medium for mutants screening when needed: $50 \mu \mathrm{g} / \mathrm{mL}$ kanamycin or $30 \mu \mathrm{g} / \mathrm{mL}$ chloramphenicol for E. coli , $10 \mu \mathrm{g} / \mathrm{mL}$ kanamycin or $15 \mu \mathrm{g} / \mathrm{mL}$ chloramphenicol for C. glutamicum .

For the shaking flask fermentation experiment, the correct monoclonal strains were activated twice on the LB medium for $36 \mathrm{~h}$, and then the appropriate amount of bacterial seed was inoculated into a $100 \mathrm{~mL}$ flask containing $10 \mathrm{~mL}$ of seed solution. The seed medium contains glucose $30 \mathrm{~g} / \mathrm{L}$, corn steep liquor $10 \mathrm{~g} / \mathrm{L}$, yeast extract $10 \mathrm{~g} / \mathrm{L},\left(\mathrm{NH}_{4}\right)_{2} \mathrm{SO}_{4} 15 \mathrm{~g} / \mathrm{L}, \mathrm{MgSO}_{4} 2.5 \mathrm{~g} / \mathrm{L}, \mathrm{KH}_{2} \mathrm{PO}_{4} 1 \mathrm{~g} / \mathrm{L}, \mathrm{K}_{2} \mathrm{HPO}_{4} 0.5 \mathrm{~g} / \mathrm{L}, \mathrm{Na}_{2} \mathrm{HPO}_{4} \cdot 12 \mathrm{H}_{2} \mathrm{O}$ $1.26 \mathrm{~g} / \mathrm{L}$ and $\mathrm{CaCO}_{3} 10 \mathrm{~g} / \mathrm{L}$, the $\mathrm{pH}$ was adjusted to 6.7 (Supplementary Information: Figure S1). The monoclonal strains were incubated at $30^{\circ} \mathrm{C}, 220 \mathrm{rpm}$ for $11 \mathrm{~h}$. Take an appropriate amount of seed solution and inoculate it in a $250 \mathrm{~mL}$ Erlenmeyer flask containing $20 \mathrm{~mL}$ of fermentation medium so that the $\mathrm{OD}_{600}$ of the initial fermentation solution is 1 at $600 \mathrm{~nm}$. The fermentation medium contains xylose $100 \mathrm{~g} / \mathrm{L}$ or glucose $70 \mathrm{~g} / \mathrm{L}$ and xylose $30 \mathrm{~g} / \mathrm{L}$, yeast extract $6 \mathrm{~g} / \mathrm{L},\left(\mathrm{NH}_{4}\right)_{2} \mathrm{SO}_{4} 50 \mathrm{~g} / \mathrm{L}, \mathrm{MgSO}_{4} 2.5 \mathrm{~g} / \mathrm{L}, \mathrm{KH}_{2} \mathrm{PO}_{4} 1 \mathrm{~g} / \mathrm{L}$, $\mathrm{K}_{2} \mathrm{HPO}_{4} 0.5 \mathrm{~g} / \mathrm{L}, \mathrm{Na}_{2} \mathrm{HPO}_{4} \cdot 12 \mathrm{H}_{2} \mathrm{O} 1.26 \mathrm{~g} / \mathrm{L}, \mathrm{MnSO}_{4} \cdot \mathrm{H}_{2} \mathrm{O} 0.02 \mathrm{~g} / \mathrm{L}, \mathrm{FeSO}_{4} \cdot 7 \mathrm{H}_{2} \mathrm{O} 0.02 \mathrm{~g} / \mathrm{L}$, biotin $0.9 \mu \mathrm{M}$, 
thiamine- $\mathrm{HCl} 15 \mu \mathrm{M}$ and $\mathrm{CaCO}_{3} 10 \mathrm{~g} / \mathrm{L}$, while the $\mathrm{pH}$ was adjusted to 6.7. The strains in fermentation medium were incubated at $31.5^{\circ} \mathrm{C}, 250 \mathrm{rpm}$ for $72 \mathrm{~h}$.

\section{Analytical methods of cell growth and fermentation products}

Every 12 hours, three parallel samples $(100 \mu \mathrm{L})$ were taken to monitor the bacteria density, consumption of glucose and xylose, and L-ornithine production. The $\mathrm{OD}_{600}$ value was detected to assess the cell growth by a microplate reader (BioTek Instruments, Winooski, VT, USA) after adding $0.125 \mathrm{~mol} / \mathrm{L} \mathrm{HCl}$ to dissolve $\mathrm{CaCO}_{3}$ (Zhang et al., 2019). The samples were centrifuged to obtain fermentation supernatant. The glucose concentration was analyzed by SBA-40E biosensor analyzer (Institute of Biology, Shandong Academy of Sciences, Jinan, Shandong, China). The level of xylose consumption was determined by high-performance liquid chromatography (HPLC) (Chen, Zhu, \& Xia, 2014; Yim et al., 2013). The content of L-ornithine was determined by ninhydrin colorimetry (B. Zhang, M. Yu, Y. Zhou, et al., 2018). All experiments had triple parallels, and data are repressed as mean and standard deviation (SD).

\section{RESULTS AND DISCUSSION}

Comparison with the xylose utilization capacity of xylose isomerases and xylulose kinases from different sources

Xylose isomerase $(x y l A)$ and xylulose kinase $(x y l B)$ exist in the form of gene clusters. The xylose isomerase metabolic pathway from different sources established in C. glutamicum have different xylose utilization capacities, this might be the result of the genetic codon preference between the $x y l A B$ source strain and $C$. glutamicum (Meiswinkel et al., 2013). The xylAB genes derived from E. coli MG1655 and X. campestris were expressed under IPTG induced vector pXMJ19, in which the $\mathrm{P}_{\text {tac }}$ is the promoter for gene expression. The resulting expression plasmids were labeled $\mathrm{p} 19 \mathrm{P}_{\text {lac }}-\mathrm{EcoAB}$ and $\mathrm{p} 19 \mathrm{P}_{\mathrm{tac}}-\mathrm{XcaAB}$. The two plasmids were transformed into C. glutamicum SO26, resulted the C. glutamicum EAB and XAB. Fig.2a showed the growth curve and xylose consumption of strain $\mathrm{EAB}$ and $\mathrm{XAB}$ during $72 \mathrm{~h}$ fermentation. The results indicated that $x y l A B$ from $X$. campestris achieved higher xylose consumption $(45.1 \mathrm{~g} / \mathrm{L})$ compared with $x y l A B$ from $E$. coli MG1655 (25.0 g/L). The growth $\mathrm{OD}_{600}$ increased from 12.05 (EAB) to 12.95 (XAB). The L-ornithine concentration in the supernatant of fermentation was determined (Fig.2b). The L-ornithine production titer of the strain XAB $(21.6 \pm 0.19 \mathrm{~g} / \mathrm{L})$ is $18.7 \%$ higher than strain EAB $(18.2 \pm 0.35 \mathrm{~g} / \mathrm{L})$, and the corresponding xylose yield of XAB is $0.48 \mathrm{~g} / \mathrm{g}$. The C. glutamicum XAB demonstrated the better capacity of xylose utilization and L-ornithine synthesis than strain EAB.

Knocking-in the pentose transporter demonstrates the promotion of xylose utilization and L-ornithine production

In order to increase the rate of xylose consumption, the pentose transporter gene (araE) from Bacillus subtilis was integrated into the genome locus of iolR with the strong $\mathrm{P}_{\text {eftu }}$ promoter, to generate the strain termed as $\mathrm{XAB01}$. The pentose transporter AraE is not only extremely significant for the arabinose transportation, but also promotes the transportation of xylose to cells (Mao et al., 2018). As expected, the results showed that strain XAB01 demonstrated superior xylose consumption and L-ornithine synthesis than strain XAB (Fig.3a and $3 \mathrm{~b}$ ). strain XAB01 consumed $47.9 \mathrm{~g} / \mathrm{L}$ xylose after $72 \mathrm{~h}$ fermentation, with an average consumption rate of $0.665 \mathrm{~g} /(\mathrm{L} \cdot \mathrm{h})$. Through the rapid utilization of xylose, the growth and L-ornithine yield of strain were also improved. The output of L-ornithine increased by $12.5 \%(24.3 \pm 0.23 \mathrm{~g} / \mathrm{L})$ compared with strain XAB, and the xylose yield is $0.51 \mathrm{~g} / \mathrm{g}$. 


\section{Effect of modification of phosphoenolpyruvate carboxylase on the production of L-ornithine}

Phosphoenolpyruvate carboxylase (PEPC) is an enzyme in the glycolysis pathway of C. glutamicum and plays an important role in the regulation of the TCA cycle (Fig.1). Phosphoenolpyruvate and carbon dioxide synthesize oxaloacetic acid under the catalysis of PEPC, and then oxaloacetic acid enters the TCA cycle for further metabolism. The expression and activity of PEPC affect the synthesis of glutamic acid in $C$. glutamicum (Nagano-Shoji et al., 2017; Wada et al., 2015). Lysine at position 653 (K653) is essential for the regulation of PEPC acetylation. Megumi ed al. found that acetylation of PEPC at K653 decreased enzymatic activity and reduced glutamate production, this means K653-acetylation regulates PEPC activity negatively. Mutated K653 into arginine can lower the level of acetylation on PEPC, which correspondingly improve its activity (Nagano-Shoji et al., 2017). In addition, PEPC will be feedback suppressed by aspartic acid when it is overexpressed in C. glutamicum, mutated aspartic acid at position 299 of PEPC to asparagine with a similar structure can effectively reduce the inhibitory effect (Wada et al., 2015). In our study, we attempt to combine the weakening acetylation by K653R and the attenuating feedback inhibition by D299N of PEPC to enhance the activity of this enzyme, leading to promote the glutamate synthesis and the L-ornithine yield. We selected the more preferred CGC and AAC codons in C. glutamicum S9114 to mutate K653 and D299. At the same time, the pepc gene was overexpressed by adding a strong constitutive promoter H36 (Yim et al., 2013). Multiple gene fragments are fused into a complete fragment by PCR overlapping amplification technology. After two point mutations in pepc, strain XAB03 was constructed. The shaking flask fermentation of strain XAB03 showed that the production of L-ornithine was $27.1 \pm 0.32 \mathrm{~g} / \mathrm{L}$, which was $11.5 \%$ higher than that of strain XAB01 (Fig.4b). Moreover, it has a positive effect on the growth of C. glutamicum (Fig.4a). These results indicate the importance of PEPC in L-ornithine synthesis, and this modification strategy shows value for the synthesis of L-glutamate, L-citrulline and L-arginine.

\section{Addition of biotin and thiamine hydrochloride accelerates the syn- thesis of L-ornithine}

In addition to the modification of key enzymes in metabolic pathways, the addition of key coenzymes is also an important method to promote the synthesis of products (Y. Cao, Duan, \& Shi, 2014). Biotin and thiamine hydrochloride are the coenzymes of carboxylase in the metabolic process. Biotin plays an important role in the metabolism of bacterial proteins, which could change the content of cell membrane components and permeability. Different concentrations of biotin affect the transcription levels of enzymes and promote the synthesis of glutamate (Y. Cao et al., 2014; Yan Cao, Mpofu, Jian, \& Zuoying, 2012). In order to further optimize the fermentation process, we attempted to adding the coenzyme during the L-ornithine production. The concentration of biotin and thiamine hydrochloride in the fermentation medium was $0.9 \mu \mathrm{M}$ and 15 $\mu \mathrm{M}$ (Hyun Jin, Myung Cho, \& Hoon Park, 2007), and the L-ornithine production increased to $33.4 \mathrm{~g} / \mathrm{L}$ compared with no adding coenzyme fermentation (27.1 g/L) (Fig.5). During the $0-48 \mathrm{~h}$ fermentation period in shake flasks, the strain XAB03 grows with abundant nutrients, the energy distribution mainly focuses on the growth of the bacteria while the production of L-ornithine is weak. From 48-72 h, the growth tends to be stable and the L-ornithine is synthesized rapidly. The results provide a research direction for the promotion of certain target products through the addition of coenzymes and some small molecules.

\section{Effects of a combination of glucose and xylose on L-ornithine}

Metabolism of different sugars is an important basement for the lignocellulose utilization. Glucose and xylose are the most important six- and five-carbon sugars in the hydrolysis of lignocellulose. We compared L-ornithine yield in different ratios of glucose and xylose in the case of the total sugar concentration was 
constant. On the premise that the total sugar concentration is $100 \mathrm{~g} / \mathrm{L}$, seven groups of different glucose concentration gradients were chosen (Fig.5). The mixed carbon sources showed the advantage of L-ornithine yield compared with using glucose or xylose as the sole carbon source. The results showed that the maximum L-ornithine production could be obtained $(41.5 \pm 0.02 \mathrm{~g} / \mathrm{L})$ when glucose is $70 \mathrm{~g} / \mathrm{L}$ and xylose is $30 \mathrm{~g} / \mathrm{L}$ (Fig.5 b, c).

Based on all the above conditions, the $\mathrm{OD}_{600}$ and L-ornithine production of strain XAB03 could reach to $16.8 \pm 0.19$ and $41.5 \mathrm{~g} / \mathrm{L}$ (Fig.6c) respectively after shake flask fermentation for $72 \mathrm{~h}$, which is the highest titer so far to the best of our knowledge (Table 2), 7.8\% higher than Zhang et al. had reported, and increased by $43.4 \%$ compared with the sole xylose carbon source (Zhang et al., 2019). The 2:1 ratio is close to the ratio of glucose to xylose after lignocellulose hydrolysis. This result lays a foundation for the feasibility and superiority of L-ornithine synthesis from lignocellulose hydrolysate.

\section{CONCLUSION}

In this study, $x y l A B$ operon was introduced into C. glutamicum SO26 to achieve the consumption of xylose for the production of L-ornithine. And then, we verified the AraE, the reduction in the degree of acetylation and the release of feedback inhibition of aspartic acid of PEPC, the addition of biotin and thiamine hydrochloride, the resulting strain C. glutamicum XAB03 has reached $41.5 \mathrm{~g} / \mathrm{L}$ shaker flask output from glucose and xylose. This work also shows the possibility of making full use of lignocellulose for the synthesis of L-ornithine and lays the foundation for the further realization of industrialized strain production.

\section{FUNDING SOURCES}

This research was supported and funded by the National Key Research and Development Project (Grant no. 2018YFA0900404), the National Natural Science Foundation of China (Grant no. 31730004) and the Shanghai Municipal Science and Technology Commission Project (18JC1410802).

\section{ACKNOWLEDGMENT}

We would like to thank Dr. Li-Ming Liu for providing us withCorynebacterium glutamine S9114.

\section{REFERENCES}

Becker, J., Rohles, C. M., \& Wittmann, C. (2018). Metabolically engineered Corynebacterium glutamicum for bio-based production of chemicals, fuels, materials, and healthcare products. Metab Eng, 50 , 122-141. doi:10.1016/j.ymben.2018.07.008

Becker, J., \& Wittmann, C. (2015). Advanced biotechnology: metabolically engineered cells for the bio-based production of chemicals and fuels, materials, and health-care products. Angew Chem Int Ed Engl, 54 (11), 3328-3350. doi:10.1002/anie.201409033

Brusseler, C., Radek, A., Tenhaef, N., Krumbach, K., Noack, S., \& Marienhagen, J. (2018). The myoinositol/proton symporter IolT1 contributes to d-xylose uptake in Corynebacterium glutamicum.Bioresour Technol, 249 , 953-961. doi:10.1016/j.biortech.2017.10.098

Buschke, N., Becker, J., Schafer, R., Kiefer, P., Biedendieck, R., \& Wittmann, C. (2013). Systems metabolic engineering of xylose-utilizing Corynebacterium glutamicum for production of 1,5-diaminopentane.Biotechnol J, 8 (5), 557-570. doi:10.1002/biot.201200367 
Buschke, N., Schafer, R., Becker, J., \& Wittmann, C. (2013). Metabolic engineering of industrial platform microorganisms for biorefinery applications-optimization of substrate spectrum and process robustness by rational and evolutive strategies. Bioresour Technol, 135 , 544-554. doi:10.1016/j.biortech.2012.11.047

Butterworth, R. F. (2020). Beneficial effects of L-ornithine L-aspartate for prevention of overt hepatic encephalopathy in patients with cirrhosis: a systematic review with meta-analysis. Metab Brain Dis, 35 (1), 75-81. doi:10.1007/s11011-019-00463-8

Cao, Y., Duan, Z., \& Shi, Z. (2014). Effect of biotin on transcription levels of key enzymes and glutamate efflux in glutamate fermentation by Corynebacterium glutamicum. World J Microbiol Biotechnol, 30 (2), 461-468. doi:10.1007/s11274-013-1468-0

Cao, Y., Mpofu, E., Jian, D., \& Zuoying, D. (2012). Activity changes of key enzymes in glutamate fermentation in response to varying initial biotin contents. CIESC JOURNAL, 63 . doi:10.3969/j.issn.04381157.2012.07.028

Chen, T., Zhu, N., \& Xia, H. (2014). Aerobic production of succinate from arabinose by metabolically engineered Corynebacterium glutamicum.Bioresour Technol, 151 , 411-414. doi:10.1016/j.biortech.2013.10.017

Das, A., Fröhlich, D., Achanta, L. B., Rowlands, B. D., Housley, G. D., Klugmann, M., \& Rae, C. D. (2020). L-Aspartate, L-Ornithine and L-Ornithine-L-Aspartate (LOLA) and Their Impact on Brain Energy Metabolism. Neurochem Res, 45 (6), 1438-1450. doi:10.1007/s11064-020-03044-9

Davies, N. A., Wright, G., Ytrebø, L. M., Stadlbauer, V., Fuskevåg, O. M., Zwingmann, C., Jalan, R. (2009). L-ornithine and phenylacetate synergistically produce sustained reduction in ammonia and brain water in cirrhotic rats. Hepatology, 50 (1), 155-164. doi:10.1002/hep.22897

Gopinath, V., Meiswinkel, T. M., Wendisch, V. F., \& Nampoothiri, K. M. (2011). Amino acid production from rice straw and wheat bran hydrolysates by recombinant pentose-utilizing Corynebacterium glutamicum. Appl Microbiol Biotechnol, 92 (5), 985-996. doi:10.1007/s00253-011-3478-x

Gutmann, M., Hoischen, C., \& Krämer, R. (1992). Carrier-mediated glutamate secretion by Corynebacterium glutamicum under biotin limitation. Biochim Biophys Acta, 1112 (1), 115-123. doi:10.1016/00052736(92)90261-j

Hao, N., Mu, J., Hu, N., Xu, S., Shen, P., Yan, M., Xu, L. (2016). Implication of ornithine acetyltransferase activity on l-ornithine production in Corynebacterium glutamicum. Biotechnol Appl Biochem, 63 (1), 15-21. doi:10.1002/bab.1353

Hwang, G.-H., \& Cho, J.-Y. (2014). Enhancement of l-ornithine production by disruption of three genes encoding putative oxidoreductases in Corynebacterium glutamicum. J Ind Microbiol Biotechnol, 41 (3), 573-578. doi:10.1007/s10295-013-1398-8

Ikeda, M., Mizuno, Y., Awane, S., Hayashi, M., Mitsuhashi, S., \& Takeno, S. (2011). Identification and application of a different glucose uptake system that functions as an alternative to the phosphotransferase system in Corynebacterium glutamicum. Appl Microbiol Biotechnol, 90 (4), 1443-1451. doi:10.1007/s00253011-3210-x

Jensen, J. V., Eberhardt, D., \& Wendisch, V. F. (2015). Modular pathway engineering of Corynebacterium glutamicum for production of the glutamate-derived compounds ornithine, proline, putrescine, citrulline, and arginine. J Biotechnol, 214, 85-94. doi:10.1016/j.jbiotec.2015.09.017

Jiang, L. Y., Chen, S. G., Zhang, Y. Y., \& Liu, J. Z. (2013). Metabolic evolution of Corynebacterium glutamicum for increased production of L-ornithine. BMC Biotechnol, 13 , 47. doi:10.1186/1472-6750-13-47

Jiang, L. Y., Zhang, Y. Y., Li, Z., \& Liu, J. Z. (2013). Metabolic engineering of Corynebacterium glutamicum for increasing the production of L-ornithine by increasing NADPH availability. J Ind Microbiol Biotechnol, 40 (10), 1143-1151. doi:10.1007/s10295-013-1306-2 
Jo, S., Yoon, J., Lee, S.-M., Um, Y., Han, S. O., \& Woo, H. M. (2017). Modular pathway engineering of Corynebacterium glutamicum to improve xylose utilization and succinate production. Journal of Biotechnology, 258, 69-78. doi:10.1016/j.jbiotec.2017.01.015

Jojima, T., Fujii, M., Mori, E., Inui, M., \& Yukawa, H. (2010). Engineering of sugar metabolism of Corynebacterium glutamicum for production of amino acid l-alanine under oxygen deprivation. Appl Microbiol Biotechnol, 87 (1), 159-165. doi:10.1007/s00253-010-2493-7

Kim, D. J., Hwang, G. H., Um, J. N., \& Cho, J. Y. (2015). Increased L-ornithine production in Corynebacterium glutamicum by overexpression of a gene encoding a putative aminotransferase. $J$ Mol Microbiol Biotechnol, 25 (1), 45-50. doi:10.1159/000375124

Kim, H., Lee, H. S., Park, H., Lee, D. H., Boles, E., Chung, D., \& Park, Y. C. (2017). Enhanced production of xylitol from xylose by expression of Bacillus subtilis arabinose:H(+) symporter and Scheffersomyces stipitis xylose reductase in recombinant Saccharomyces cerevisiae. Enzyme Microb Technol, 107 , 7-14. doi:10.1016/j.enzmictec.2017.07.014

Kim, S. Y., Lee, J., \& Lee, S. Y. (2015). Metabolic engineering of Corynebacterium glutamicum for the production of L-ornithine.Biotechnol Bioeng, 112 (2), 416-421. doi:10.1002/bit.25440

Lee, Y.-J., \& Cho, J.-Y. (2006). Genetic manipulation of a primary metabolic pathway for l-ornithine production in Escherichia coli.Biotechnology Letters, 28 (22), 1849-1856. doi:10.1007/s10529-006-9163-y

Lindner, S. N., Petrov, D. P., Hagmann, C. T., Henrich, A., Kramer, R., Eikmanns, B. J., Seibold, G. M. (2013). Phosphotransferase system-mediated glucose uptake is repressed in phosphoglucoisomerase-deficient Corynebacterium glutamicum strains. Appl Environ Microbiol, 79 (8), 2588-2595. doi:10.1128/aem.03231-12

Lindner, S. N., Seibold, G. M., Henrich, A., Kramer, R., \& Wendisch, V. F. (2011). Phosphotransferase system-independent glucose utilization in corynebacterium glutamicum by inositol permeases and glucokinases.Appl Environ Microbiol, 77 (11), 3571-3581. doi:10.1128/aem.02713-10

Mao, Y., Li, G., Chang, Z., Tao, R., Cui, Z., Wang, Z., Zhao, X. (2018). Metabolic engineering of Corynebacterium glutamicum for efficient production of succinate from lignocellulosic hydrolysate.Biotechnol Biofuels, 11 , 95. doi:10.1186/s13068-018-1094-z

Matsuo, H., Iwamoto, A., Otsuka, T., Hishida, Y., Akiduki, S., Aoki, M., Yasuo, S. (2015). Effects of time of L-ornithine administration on the diurnal rhythms of plasma growth hormone, melatonin, and corticosterone levels in mice. Chronobiol Int, 32 (2), 225-234. doi:10.3109/07420528.2014.965312

Meiswinkel, T. M., Gopinath, V., Lindner, S. N., Nampoothiri, K. M., \& Wendisch, V. F. (2013). Accelerated pentose utilization by Corynebacterium glutamicum for accelerated production of lysine, glutamate, ornithine and putrescine. Microb Biotechnol, 6 (2), 131-140. doi:10.1111/1751-7915.12001

Nagano-Shoji, M., Hamamoto, Y., Mizuno, Y., Yamada, A., Kikuchi, M., Shirouzu, M., Kosono, S. (2017). Characterization of lysine acetylation of a phosphoenolpyruvate carboxylase involved in glutamate overproduction in Corynebacterium glutamicum. Mol Microbiol, 104 (4), 677-689. doi:10.1111/mmi.13658

Park, S. H., Kim, H. U., Kim, T. Y., Park, J. S., Kim, S. S., \& Lee, S. Y. (2014). Metabolic engineering of Corynebacterium glutamicum for L-arginine production. Nat Commun, 5 , 4618. doi:10.1038/ncomms5618

Qin, J., Zhou, Y. J., Krivoruchko, A., Huang, M., Liu, L., Khoomrung, S., Nielsen, J. (2015). Modular pathway rewiring of Saccharomyces cerevisiae enables high-level production of L-ornithine. Nat Commun, 6 , 8224. doi:10.1038/ncomms9224

Sakamoto, K., Mori, A., Nakahara, T., Morita, M., \& Ishii, K. (2015). Effect of long-term treatment of L-ornithine on visual function and retinal histology in the rats. Biol Pharm Bull, 38 (1), 139-143. doi:10.1248/bpb.b14-00491 
Sasaki, M., Jojima, T., Inui, M., \& Yukawa, H. (2008). Simultaneous utilization of D-cellobiose, D-glucose, and D-xylose by recombinant Corynebacterium glutamicum under oxygen-deprived conditions. Appl Microbiol Biotechnol, 81 (4), 691-699. doi:10.1007/s00253-008-1703-z

Schneider, J., Niermann, K., \& Wendisch, V. F. (2011). Production of the amino acids l-glutamate, l-lysine, l-ornithine and l-arginine from arabinose by recombinant Corynebacterium glutamicum. J Biotechnol, 154 (2-3), 191-198. doi:10.1016/j.jbiotec.2010.07.009

Shu, Q., Xu, M., Li, J., Yang, T., Zhang, X., Xu, Z., \& Rao, Z. (2018). Improved l-ornithine production in Corynebacterium crenatum by introducing an artificial linear transacetylation pathway. $J$ Ind Microbiol Biotechnol, 45 (6), 393-404. doi:10.1007/s10295-018-2037-1

Sivashanmugam, M., J, J., V, U., \& K, N. S. (2017). Ornithine and its role in metabolic diseases: An appraisal. Biomed Pharmacother, 86 , 185-194. doi:10.1016/j.biopha.2016.12.024

Vargas-Ramírez, A. L., Medina-Enríquez, M. M., Cordero-Rodríguez, N. I., Ruiz-Cuello, T., Aguilar-Faisal, L., Trujillo-Ferrara, J. G., Rodríguez-Páez, L. (2016). N- $\omega$-chloroacetyl-L-ornithine has in-vitro activity against cancer cell lines and in-vivo activity against ascitic and solid tumors. Anticancer Drugs, 27 (6), 508-518. doi:10.1097/cad.0000000000000353

Wada, M., Sawada, K., Ogura, K., Shimono, Y., Hagiwara, T., Sugimoto, M., Yokota, A. (2015). Effects of phosphoenolpyruvate carboxylase desensitization on glutamic acid production in Corynebacterium glutamicum ATCC 13032. Journal of bioscience and bioengineering, 121 . doi:10.1016/j.jbiosc.2015.06.008

Wendisch, V. F., Brito, L. F., Gil Lopez, M., Hennig, G., Pfeifenschneider, J., Sgobba, E., \& Veldmann, K. H. (2016). The flexible feedstock concept in Industrial Biotechnology: Metabolic engineering of Escherichia coli, Corynebacterium glutamicum, Pseudomonas, Bacillus and yeast strains for access to alternative carbon sources. J Biotechnol, 234, 139-157. doi:10.1016/j.jbiotec.2016.07.022

Wu, X. Y., Guo, X. Y., Zhang, B., Jiang, Y., \& Ye, B. C. (2019). Recent Advances of L-ornithine Biosynthesis in Metabolically Engineered Corynebacterium glutamicum. Front Bioeng Biotechnol, 7 , 440. doi:10.3389/fbioe.2019.00440

Xu, J., Zhang, J., Liu, D., \& Zhang, W. (2016). Increased glucose utilization and cell growth of Corynebacterium glutamicum by modifying the glucose-specific phosphotransferase system (PTS(Glc)) genes. Can $J$ Microbiol, 62 (12), 983-992. doi:10.1139/cjm-2016-0027

Yim, S. S., An, S. J., Kang, M., Lee, J., \& Jeong, K. J. (2013). Isolation of fully synthetic promoters for high-level gene expression inCorynebacterium glutamicum. Biotechnology and Bioengineering, 110 (11), 2959-2969. doi:10.1002/bit.24954

Zhang, B., Gao, G., Chu, X. H., \& Ye, B. C. (2019). Metabolic engineering of Corynebacterium glutamicum S9114 to enhance the production of l-ornithine driven by glucose and xylose. Bioresour Technol, 284 , 204-213. doi:10.1016/j.biortech.2019.03.122

Zhang, B., Ren, L. Q., Yu, M., Zhou, Y., \& Ye, B. C. (2018). Enhanced l-ornithine production by systematic manipulation of l-ornithine metabolism in engineered Corynebacterium glutamicum S9114.Bioresour Technol, 250 , 60-68. doi:10.1016/j.biortech.2017.11.017

Zhang, B., Yu, M., Wei, W. P., \& Ye, B. C. (2018). Optimization of L-ornithine production in recombinant Corynebacterium glutamicum S9114 by cg3035 overexpression and manipulating the central metabolic pathway.17 (1), 91. doi:10.1186/s12934-018-0940-9

Zhang, B., Yu, M., Zhou, Y., Li, Y., \& Ye, B. C. (2017). Systematic pathway engineering of Corynebacterium glutamicum S9114 for L-ornithine production. Microb Cell Fact, 16 (1), 158. doi:10.1186/s12934-017-0776-8

Zhang, B., Yu, M., Zhou, Y., \& Ye, B. C. (2018). Improvement of L-ornithine production by attenuation of 
$\operatorname{argF}$ in engineered Corynebacterium glutamicum S9114. AMB Express, 8 (1), 26. doi:10.1186/s13568-018$0557-8$

Zhang, X., Zhang, X., Xu, G., Zhang, X., Shi, J., \& Xu, Z. (2018). Integration of ARTP mutagenesis with biosensor-mediated high-throughput screening to improve l-serine yield in Corynebacterium glutamicum. Appl Microbiol Biotechnol, 102 (14), 5939-5951. doi:10.1007/s00253-018-9025-2

Zhou, Z., Wang, C., Xu, H., Chen, Z., \& Cai, H. (2015). Increasing succinic acid production using the PTS-independent glucose transport system in a Corynebacterium glutamicum PTS-defective mutant. J Ind Microbiol Biotechnol, 42 (7), 1073-1082. doi:10.1007/s10295-015-1630-9

\section{GRAPHICAL ABSTRACT}

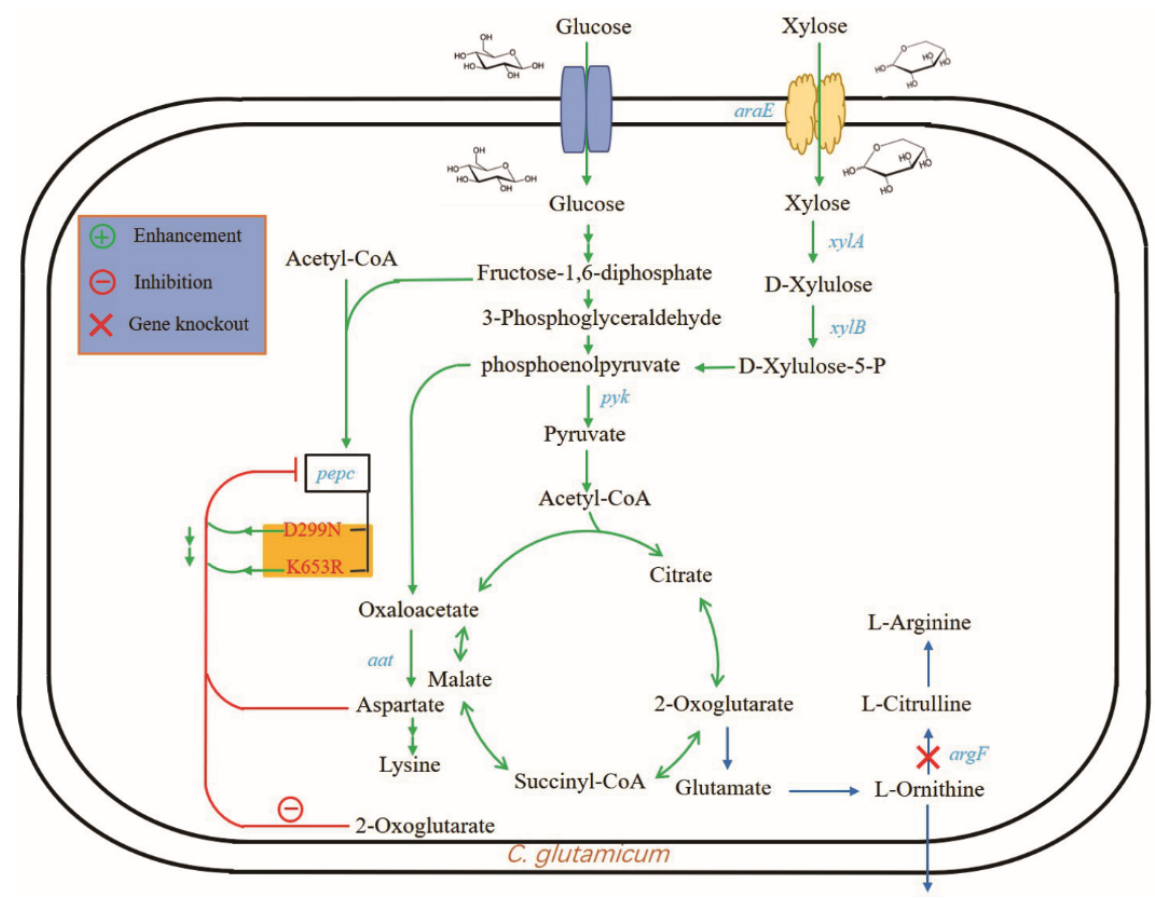

Fig.1. Schematic diagram of the metabolic engineering process of C. glutamicum .

pepc encodes phosphoenolpyruvate carboxylase; $p y k$ encodes pyruvate kinase; $x y l A$ encodes xylose isomerase; $x y l B$ encodes xylulose kinase; aat encodes aspartate aminotransferase; ara $E$ encodes pentose transporter; $\arg F$ encodes N-ornithine carbamoyl transferase.

Table 1. Strains and plasmids

Strains/plasmids Relevant characteristics

Strains

E. coli DH5a

E. coli K-12 MG1655

$X$. campestris

C. glutamicum $\mathrm{SO} 26$

Bacillus subtilis

C. glutamicum $\mathrm{pX}$

C. glutamicum EAB

C. glutamicum XAB
Clone host strain

The source of Eco- $x y l A B$ genes

The source of Xca- $x y l A B$ genes

Deletion of $\operatorname{argF}, n c g l 1221, \arg R$, putP, iolR, and $m s c C G 2$; attenuation of odhA, proB, pta, cat, al The source of pentose transporter araE gene

C. glutamicum SO26 with pXMJ19

C. glutamicum $\mathrm{SO} 26$ with $\mathrm{p} 19 \mathrm{P}_{\text {lac }}-\mathrm{EcoAB}$

C. glutamicum SO26 with $\mathrm{p} 19 \mathrm{P}_{\mathrm{lac}}-\mathrm{XcaAB}$ 


\begin{tabular}{|c|c|}
\hline Strains/plasmids & Relevant characteristics \\
\hline C. glutamicum XAB01 & AB with the knocking of araE gene into the locus of iolR \\
\hline C. glutamicum XAB02 & $\mathrm{XAB01with} \mathrm{P}_{\mathrm{H} 36}$ promoter in the upstream of pepc gene and 1957-1959 bp CGC \\
\hline C. glutamicum XAB03 & XAB02 with 895-897 bp AAC replaces GAT in pepc gene \\
\hline Plasmids & \\
\hline pK18mobsacB & The suicide vector containing the $B$. subtilis sacB gene; $\mathrm{kan}^{\mathrm{R}}$, allows for selection of double crc \\
\hline pXMJ19 & High copy expression vector, $\mathrm{Cm}^{\mathrm{R}}$, LacIq promoter,tac promoter \\
\hline p19P $\mathrm{P}_{\text {lac }}-\mathrm{EcoAB}$ & A derivative of pXMJ19, harboringthe $x y l A B$ operon from E. coli MG1655 \\
\hline p19P $\mathrm{P}_{\text {lac }}-\mathrm{XcaAB}$ & A derivative of pXMJ19, harboringthe $x y l A B$ operon from $X$. campestris \\
\hline pk18- $\mathrm{P}_{\mathrm{eftu}^{-}}{ }^{i}$ olR $::$ ara $E$ & Using pK18mobsacB and araE to connect through the upper and lower homology arms of iolR, \\
\hline pk18-P $\mathrm{H}_{36}$-pepcTI & A originated from pK18mobsacB, add $\mathrm{P}_{\mathrm{H} 36}$ promoter in the upstream of pepc gene and 1957-19 \\
\hline pk18- $\mathrm{P}_{\mathrm{H} 36}-\mathrm{pepcT} 2$ & On the basis of pk18- $\mathrm{P}_{\mathrm{H} 36}$-pepcTI, harboring $895-897 \mathrm{bp}$ AAC replaces GAT in pepc gene \\
\hline
\end{tabular}

Table 2. Synthesis of L-ornithine by $C$. glutamicum

\begin{tabular}{|c|c|c|c|c|c|}
\hline Strains & $\begin{array}{l}\text { L-ornithine } \\
\text { concentration } \\
\left(\mathrm{g} \cdot \mathrm{L}^{-1}\right) / \text { yield }\end{array}$ & Cultivation & Sugar source & Modulations & References \\
\hline $\begin{array}{l}\text { C. glutamicum } \\
\text { SJC8514 }\end{array}$ & $12.48 / \mathrm{ND}$ & $\begin{array}{l}\text { Shake flask; } \\
\text { batch }\end{array}$ & Glucose & $\begin{array}{l}\text { Overexpression } \\
\text { of } n c g l 0452 \\
\text { and } \\
\text { argCJBDmut }\end{array}$ & $\begin{array}{l}\text { (D. J. Kim et } \\
\text { al., 2015) }\end{array}$ \\
\hline $\begin{array}{l}\text { C. glutamicum } \\
\text { SJC8039 }\end{array}$ & $14 / \mathrm{ND}$ & $\begin{array}{l}\text { Shake flask; } \\
\text { batch }\end{array}$ & Glucose & $\begin{array}{l}\text { Deletion of } \\
\arg F, \text { argR, } \\
\text { and proB; } \\
\text { Blocking } \\
\text { gluconate } \\
\text { biosynthesis }\end{array}$ & $\begin{array}{l}\text { (Hwang \& } \\
\text { Cho, 2014) }\end{array}$ \\
\hline $\begin{array}{l}\text { C. glutamicum } \\
\text { YW06 }\end{array}$ & $51.5 / 0.240$ & $\begin{array}{l}\text { Bioreactor; } \\
\text { fed-batch }\end{array}$ & Glucose & $\begin{array}{l}\text { Deletion of } \\
\arg F, \arg R \\
\text { and proB; } \\
\text { Reinforcement } \\
\text { of the PPP } \\
\text { pathway flux; } \\
\text { The use of a } \\
\text { feedback- } \\
\text { resistant } \\
\text { enzyme }\end{array}$ & $\begin{array}{l}\text { (S. Y. Kim et } \\
\text { al., 2015) }\end{array}$ \\
\hline $\begin{array}{l}\text { C. glutamicum } \\
\text { ORN1 } \\
\text { (pVWEx1- } \\
\text { araBAD) }\end{array}$ & $25.8 / 0.78$ & Shake flask & $\begin{array}{l}\text { Glucose, } \\
\text { arabinose }\end{array}$ & $\begin{array}{l}\text { Deletion of } \arg F, \\
\arg R \text {; in-frame } \\
\text { deletion of } \arg F \\
\text { and } \arg R, \\
\text { auxotrophic for } \\
\text { l-arginine }\end{array}$ & $\begin{array}{l}\text { (Schneider, } \\
\text { Niermann, \& } \\
\text { Wendisch, 2011) }\end{array}$ \\
\hline
\end{tabular}




\begin{tabular}{|c|c|c|c|c|c|}
\hline Strains & $\begin{array}{l}\text { L-ornithine } \\
\text { concentration } \\
\left(\mathrm{g} \cdot \mathrm{L}^{-1}\right) / \text { yield }\end{array}$ & Cultivation & Sugar source & Modulations & References \\
\hline $\begin{array}{l}\text { C. glutamicum } \\
\text { [?]APE6937R42 }\end{array}$ & $24.1 / 0.298$ & $\begin{array}{l}\text { Bioreactor; } \\
\text { batch }\end{array}$ & Glucose & $\begin{array}{l}\text { Deletion of } \\
\arg F, \arg R, \\
\text { and proB; } \\
\text { Adaptive } \\
\text { evolution in } \\
\text { presence of } \\
\text { L-ornithine }\end{array}$ & $\begin{array}{l}\text { (Jiang, Chen, } \\
\text { et al., 2013) }\end{array}$ \\
\hline $\begin{array}{l}\text { C. glutamicum } \\
\text { [?] APE::rocG }\end{array}$ & $14.8 / \mathrm{ND}$ & $\begin{array}{l}\text { Shake flask; } \\
\text { batch }\end{array}$ & Glucose & $\begin{array}{l}\text { Deletion of } \\
\arg F, \text { proB, } \\
\text { speE }:: \text { Ptac-M- } \\
\operatorname{roc} G, \\
\arg R:: \text { Ptac-M- } \\
\operatorname{gap} C\end{array}$ & $\begin{array}{l}\text { (Jiang, Zhang, } \\
\text { et al., 2013) }\end{array}$ \\
\hline $\begin{array}{l}\text { C. glutamicum } \\
\text { ORN6 }\end{array}$ & $20.96 / 0.524$ & $\begin{array}{l}\text { Shake flask; } \\
\text { batch }\end{array}$ & Glucose & $\begin{array}{l}\text { Deletion of } \\
\arg F, \arg R, \\
\text { and } \arg G ; \\
\text { overexpression } \\
\text { of } \arg B M ; \\
\text { attenuation of } \\
\text { pgi }\end{array}$ & $\begin{array}{l}\text { (Jensen et al., } \\
2015 \text { ) }\end{array}$ \\
\hline $\begin{array}{l}\text { C. glutamicum } \\
1006 \\
\text { [?]argR-argJ }\end{array}$ & $31.6 / 0.396$ & $\begin{array}{l}\text { Shake flask; } \\
\text { batch }\end{array}$ & Glucose & $\begin{array}{l}\text { Deletion of } \\
\arg R ; \\
\text { overexpression } \\
\text { of } \operatorname{argJ}\end{array}$ & $\begin{array}{l}\text { (Hao et al., } \\
2016)\end{array}$ \\
\hline $\begin{array}{l}\text { C. glutamicum } \\
\text { XAB03 }\end{array}$ & $41.5 / \mathrm{ND}$ & $\begin{array}{l}\text { Shake flask; } \\
\text { batch }\end{array}$ & $\begin{array}{l}\text { Glucose, } \\
\text { xylose }\end{array}$ & $\begin{array}{l}\text { C. glutamicum } \\
\text { SO26 with } \\
\text { xylAB from } X \text {. } \\
\text { campestris, } \\
\text { expression of } \\
\text { araE, } \\
\text { overexpression } \\
\text { of pepc }\end{array}$ & This study \\
\hline
\end{tabular}

a

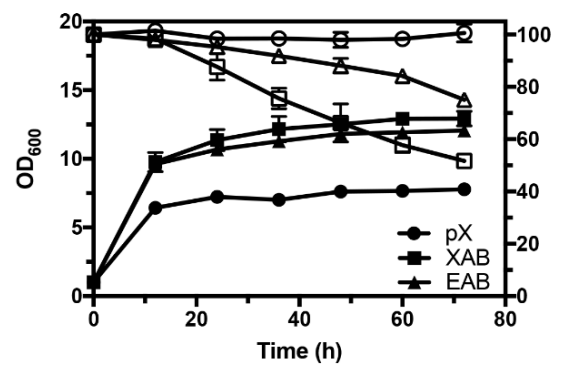

b

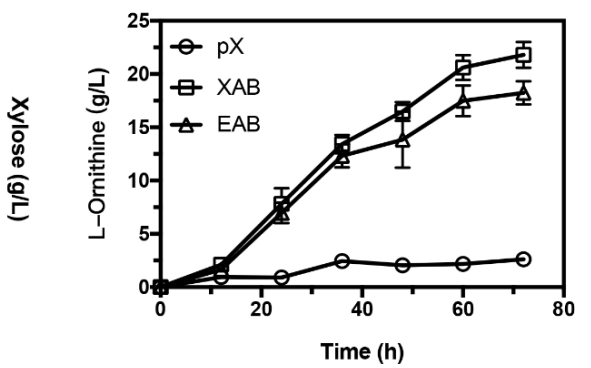

Fig.2. Comparison of the effects of $x y l A B$ genes from different strains.

a: Growth curve (solid) and xylose consumption (hollow) curves. b: L-Ornithine production curves. Strain 
pX (hollow circular) is a control strain containing pXMJ19, Strain XAB (hollow square) overexpresses $x y l A B$ from E. coil , Strain EAB (hollow upper triangle) overexpresses xylAB from X. campestris .
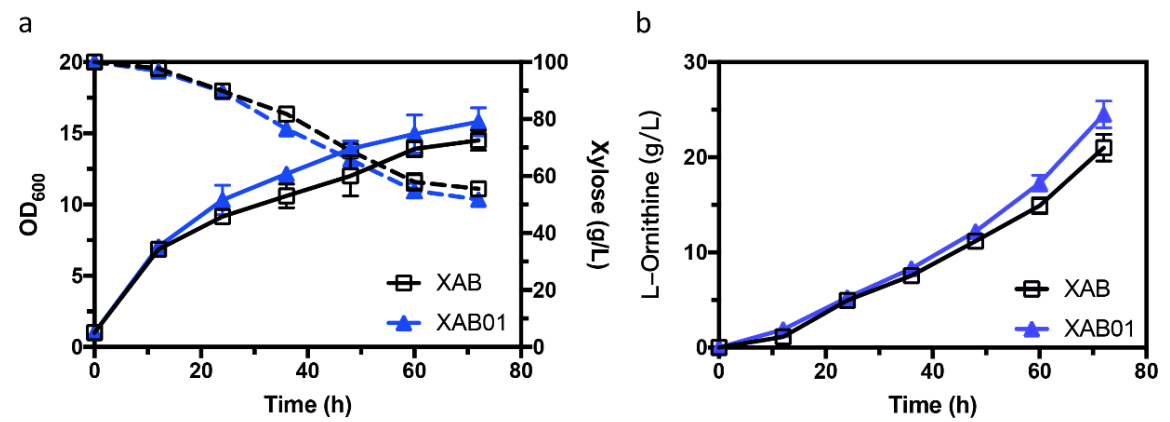

Fig.3. The promotion of araE on xylose and the effect on L-ornithine production.

a Growth and xylose consumption curves. b L-Ornithine production curves.

Strain XAB01 (blue solid triangle) integrated the araE gene fromB. subtilis with a strong promoter Peftu, and XAB (black hollow square) is the control strain.
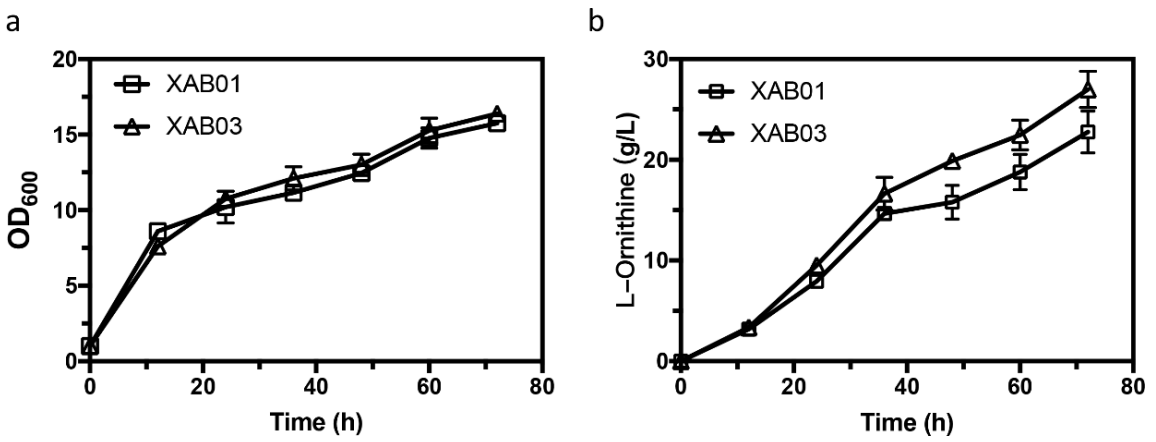

Fig.4. The PEPC modification reinforces the production of L-ornithine.

a: Growth curves. b: L-Ornithine production curves. XAB01 (hollow square) integrated the araE gene from B. subtilis with a strong promoter Peftu. XAB03 (hollow upper triangle) modifiedpepc on the basis of $\mathrm{XAB} 01$.
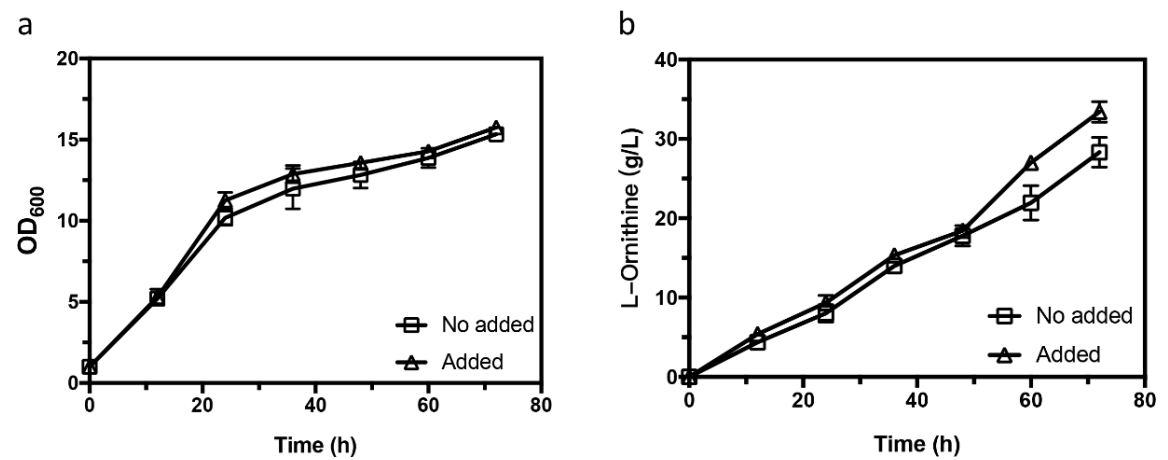

Fig.5. The effect of adding biotin and thiamine hydrochloride on L-ornithine production. a Growth curves for XAB03. b L-Ornithine production curves for XAB03. 
Added (Biotin and thiamine hydrochloride, hollow upper triangle), No added (hollow square).

a

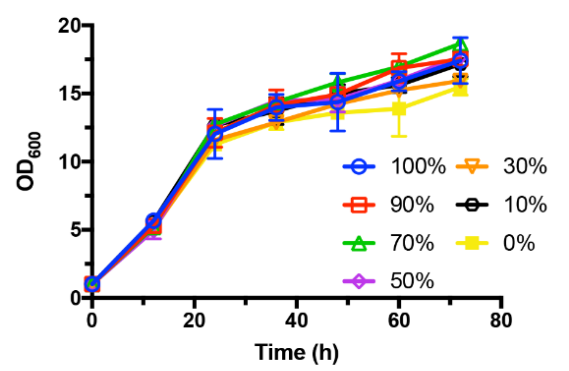

C

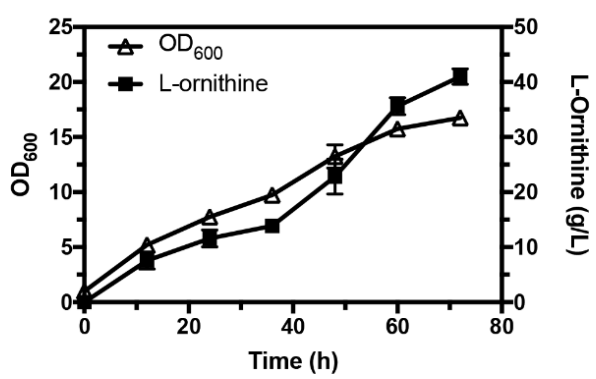

b

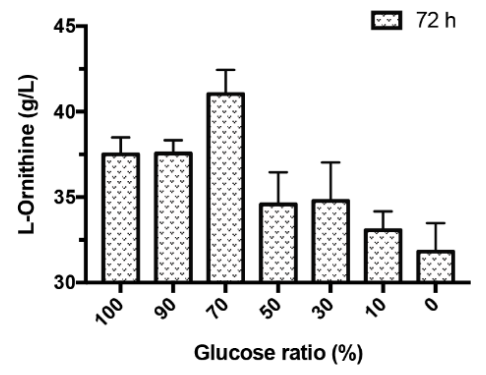

Fig.6. The effect of different ratios of glucose and xylose on L-ornithine production

a: Growth curves for C. glutamicum XAB03 at different glucose concentrations ratios (100\%, blue circle; $90 \%$, red hollow square; $70 \%$, green upper triangle; $50 \%$, purple diamond; $30 \%$, orange lower triangle; $10 \%$, black regular hexagon; 0\%, yellow solid square.). b: L-Ornithine production curves. c: Optimal shake flask fermentation experiment of C. glutamicum XAB03 in $\mathrm{OD}_{600}$ (hollow upper triangle) and L-ornithine production (solid square) in glucose $70 \mathrm{~g} / \mathrm{L}$ and xylose $30 \mathrm{~g} / \mathrm{L}$.

\section{Supplementary Information}

Table S1. Primers involved in this article

\begin{tabular}{ll}
\hline Primers & Sequence (5'-3') \\
\hline XAB-F & ggatcttccagagataagcttaaggagatatacatgagcaacaccgttttcatc \\
XAB-R & caaaacagccaaggagctctgatgaatcagccggcgtagag \\
EAB-F & caggaaacagaataattaagcttgggttgacattccgcggcattacctgattatgg \\
EAB-R & caaaacagccaagctgaattcttacgccattaatggcagaagttgc \\
up-eftu-F & ccaccgaagctccgctcgatatccacagggtagctggtagtttgaaaatc \\
araE-eftu-R & ccctcccgaatgttgagtaaagcacttcgtggtggctacgactttc \\
araE-F & gaaagtcgtagccaccacgaagtgctttactcaacattcgggaggg \\
araE-R & gaggcgcatatggaattcgatatcaacagccttcccgtagaaagg \\
up-HA-F1 & cctgcaggtcgactctagagccttccaaaggaatacttcgagaag \\
up-HA-H36-R2 & ccagatagaggtacccagcttttgaactactttaaacactctttcacattgaggg \\
up-HA-H36-F3 & ccctcaatgtgaaagagtgtttaaagtagttcaaaagctgggtacctctatctgg \\
pepc-H36-R4 & gatgtcatcgcgtagaaaatcagtcatggatccatgctactcctaccaac \\
pepc-H36-F5 & gttggtaggagtagcatgggatccatgactgattttctacgcgatgacatc \\
D299N-R6 & ctcattcatgcggttcgacaggctcagctcatg
\end{tabular}




\begin{tabular}{ll}
\hline Primers & Sequence (5'-3') \\
\hline D299N-F7 & catgagctgagcctgtcgaaccgcatgaatgag \\
down-HA-pepc-R8 & actacccaccegctggactagccggagttgcgcag \\
down-HA-pepc-F9 & ctgcgcaactccggctagtccagccgggtgggtagt \\
down-HA-R10 & tgaccatgattacgaattcagatgtacaccaggctgatgattcc \\
mutant-(K-R)-F & gggttgccgtagcgagctgagatgattcg \\
mutant-(K-R)-R & cgaaatcatctcagctcgctacggcaaccc \\
pXMJ19-F & ttgacaattaatcatcggctcgtataatgtgtg \\
pXMJ19-R & ctgatttaatctgtatcaggctgaaaatcttctctc \\
M13 fwd & cgttgtaaaacgacggccagt \\
M13 rev & acaatttcacacaggaaacagctatgac \\
\hline
\end{tabular}

a

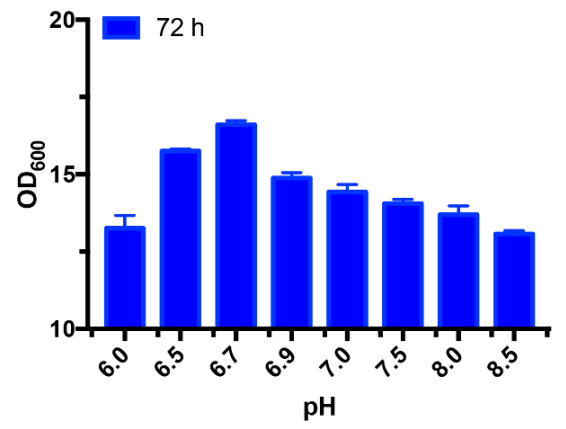

b

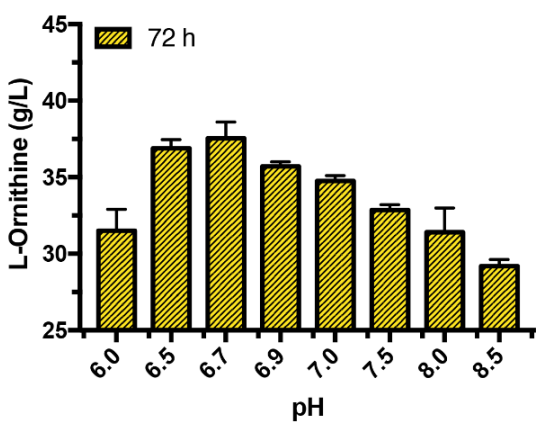

Fig. S1. Effect of different $\mathrm{pH}$ on L-ornithine yield

a Growth condition of $C$. glutamicum XAB03 at $72 \mathrm{~h}$ under different $\mathrm{pH}$. b L-Ornithine production of $C$. glutamicum XAB03 at $72 \mathrm{~h}$ under different $\mathrm{pH}$. 